\title{
A Study on the Metaphor Translation Strategies in Selected Modern Chinese Essays 1 by Zhang Peiji from the Perspective of Conceptual Blending Theory
}

\author{
Yating Zhuo ${ }^{1}$, Min Zhu ${ }^{1}$ \\ ${ }^{1}$ School of Foreign Languages, Zhejiang University of Science and Technology, Hangzhou, China \\ Correspondence: Zhuo Yating, School of Foreign Languages, Zhejiang University of Science and Technology, \\ Hangzhou, Zhejiang, China.
}

Received: July 12, 2021

doi:10.5430/elr.v10n3p55

\author{
Accepted: August 10, $2021 \quad$ Online Published: August 12, 2021 \\ URL: https://doi.org/10.5430/elr.v10n3p55
}

\begin{abstract}
According to the analytical framework of the three basic network models in Conceptual Blending Theory, this thesis dynamically presents the metaphor translation process and the choice of translation strategies in Selected Modern Chinese Essays 1 translated by Zhang Peiji. The study finds out that in Mirror Network Model, Zhang usually adopts literal translation while preserving the metaphorical image since the original metaphor shares the same organizational framework in both source culture and target culture; when it comes to One-scope Network Model, a majority of metaphorical images are omitted to achieve better readability while still some others are preserved to spread Chinese culture and introduce more cognitive models to target readers. And in both ways, paraphrases are added to deepen target readers' understanding of the source text; with regard to Two-scope Network Model, Zhang mainly adopts the translation strategy of replacement with metaphors that accord with the target language, which enables him to build a bridge between the cultures of the source language and the target language.
\end{abstract}

Keywords: conceptual blending theory, metaphor translation, prose, Selected Modern Chinese Essays 1 by Zhang Peiji, translation strategies

\section{Introduction}

Prose, on account of its own characteristics-shape dispersing but spirit concentrating, profound artistic conception, elegant and concise language, plays a significant role in the voluminous treasury of Chinese literature. Moreover, prose is widely popular among general readers and is often used as research corpus by many scholars, bringing about plentiful research achievements. In the contemporary era, more open and inclusive than before, the prose translation is increasingly important, which conduces to the spread and promotion of Chinese culture. When it comes to China's domestic prose translation, Zhang Peiji is definitely on the list because of his outstanding contributions. For instance, Selected Modern Chinese Essays I, one of his representative works, is highly praised and recommended in the Chinese translation circle in that it provides an excellent learning paradigm for translation learners, rich research materials for translation researchers, and an approach for foreign readers to appreciate Chinese literature and culture. Domestic studies on this work of translation began at the turn of the century. Since then, relevant journal articles and papers have been published basically every year, whose research objects include Zhang Peiji's translation thought, translation style, translation strategy, the translation of Chinese idioms and so forth (Xu Yanjie, 2020). As the study of metaphor translation strategies applied in the book is rare, the author will focus on it and conduct a study. Up to now, Zhang's translation of the book has been relatively little studied by scholars abroad, which possibly results from lacking the publicity and promotion of the series of books. On the one hand, we still need to facilitate Chinese literature to go global and communicate with Western culture. Since what this prose collection contains are typical prose masterpieces in contemporary China, it deserves to be known by more overseas readers and scholars; on the other hand, domestic scholars should do more researches on these works of translation so as to attract more people's attention.

Metaphor, everywhere in our daily life, is not merely a rhetorical device by its very nature, but a working mechanism that is deeply internalized and hidden in our structure for enabling us to understand concepts and things. Moreover, as a significant way for us to discover and understand the world where we live, metaphor contains rich cultural connotations and regional characteristics. Linguistic and stylistic differences pose difficulties for metaphor translation, 
while the overlapping cognitive experience of the same world brings great possibility and operability. Although fruitful research results have been achieved up to now, some deficiencies still exist in metaphor translation. First of all, the research scope is not broad enough. For example, there is a lack of research on metaphor translation strategies in prose. Secondly, some difficulties in metaphor translation still remain unsolved or even unnoticed. These difficulties involve a number of factors such as the expressiveness of language, diverse cultural traditions and different perceptions of the same object by people from diverse cultures. Therefore, the study of metaphor translation is significant and requisite since it facilitates cultural exchanges. Through the domestic and foreign study on Conceptual Blending Theory, we can learn that it is a significant, ordered, powerful, systematic and universal cognitive operation. Moreover, many studies have found that metaphor translation involves both the formation and translation of metaphor, the process of which is exactly the process of conceptual integration. And Conceptual Blending Theory has comparatively strong explanatory power for the formation and translation of metaphors. Therefore, this paper studies metaphor translation strategies from the perspective of Conceptual Blending Theory.

\section{Theoretical Framework: Conceptual Blending Theory}

On the basis of Conceptual Metaphor Theory and Mental Space Theory, Fauconnier (1997) proposed Conceptual Blending Theory in Mappings in Thought and Language, the core idea of which is to regard conceptual integration as a basic and prevalent way of human cognition that involves various aspects of our daily life. As a burgeoning theory of cognitive linguistics, it follows universal principles people hold and synthesizes research results of neuroscience, cognitive science, psychology and linguistics. Moreover, the theory studies the cognitive mechanism of meaning construction from a new perspective to give a more detailed and dynamic explanation.

\subsection{Major Concepts of Conceptual Blending Theory}

In the section, the author will introduce not only the basic network model of Conceptual Blending Theory, but also four subnetwork models that can give a strong support for the translation of various types of metaphors. Therefore, the section will lay a solid theoretical foundation for the further analysis with the combination of specific examples illustrated later.

\subsubsection{The Basic Network Model of Conceptual Blending Theory}

A significant part of Conceptual Blending Theory lies in conceptual integration network including four conceptual spaces: Input Space I, Input Space II, Generic Space and Blending Space. Moreover, Input Space I and Input Space II respectively refer to the source domain and the target domain in metaphor. The cognitive operation process of conceptual integration is described as follows: the information from different cognitive domains constitutes two input spaces, and the abstract structures or information that the two input spaces share in common form the generic space. Semantic elements in the two input spaces are matched by partial mapping across space and then selectively projected to a dynamically explicable blending space, which comprises generic structures in the generic space and partial structures extracted from the two input spaces. The integration in conceptual integration emphasizes that "the overall function should be greater than the sum of each part's function". (Li Shuai, 2020: 64) That is, the contents and concepts in the blending space are not a simple addition of the contents in different input spaces, but something new that combines background knowledge and context after incorporating projected contents of the two input spaces under a new framework.

The picture below can further illustrate the relationship between the four conceptual spaces in which black dots represent elements in each conceptual space. Full lines and dotted lines respectively show the cross-space mappings between input spaces and the projections that happen within the network. The cross-domain mappings of Input Space I and Input Space II illustrate the connection among the counterparts that pertain to two input spaces. The solid square in Blending Space refers to Emergent Structure where three correlative cognitive operation processes including the composition, the completion and the elaboration are carried out to form novel concepts. 

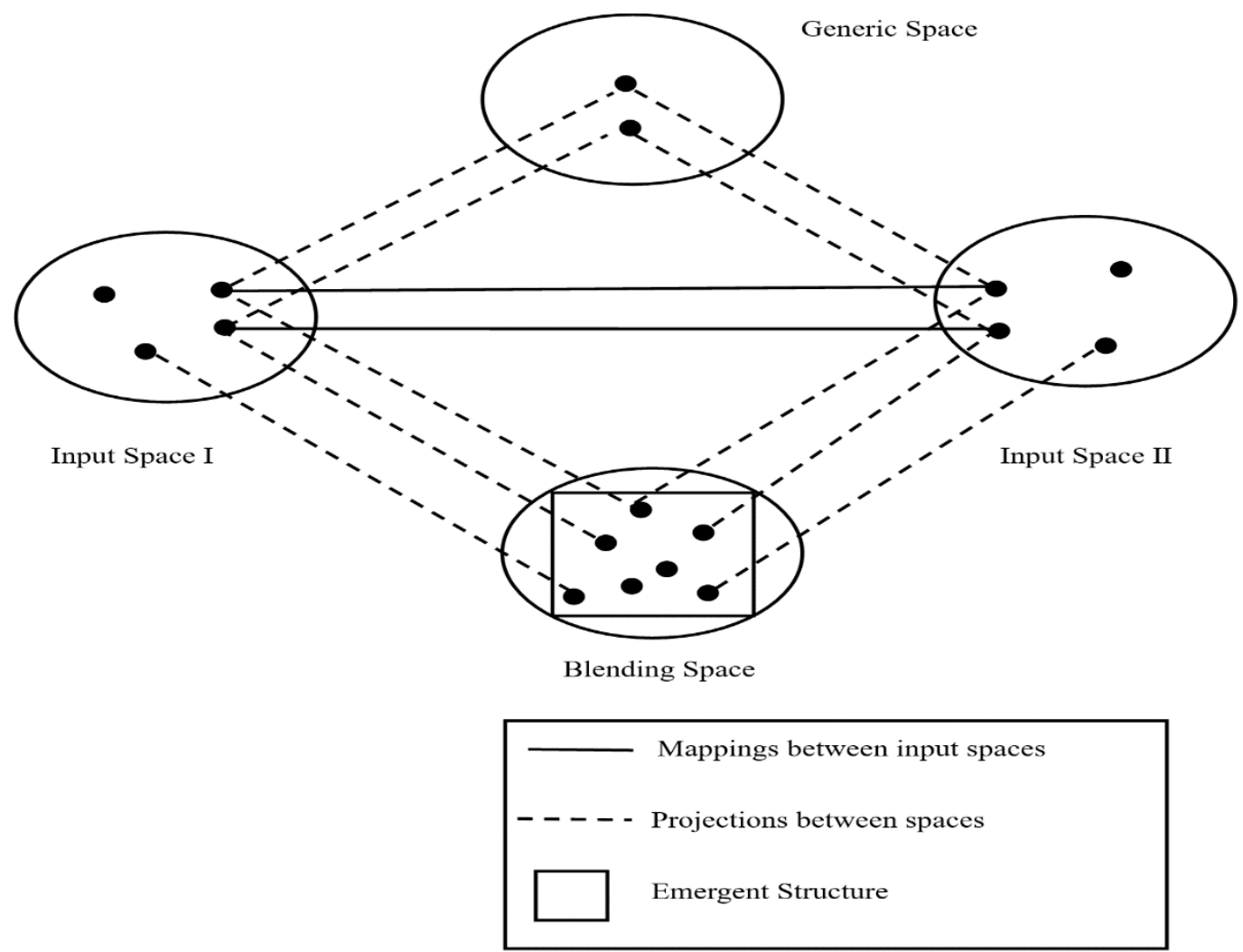

Figure 1. The Basic Network Model of Conceptual Blending Theory (Fauconnier \& Turner, 1998:143)

In this regard, it's clear that the emergent structure is the central part of conceptual integration, whose working mechanism is a dynamic cognitive process. During the process, conceptual integration is constructed based on the comprehension of context and the newly formed logic of the emergent structure. What we need to do is throw off the shackles of stereotypes using our rich imagination and activate new connections among projected elements to form novel concepts. All in all, the emergent structure is a highly abstract structure that enables us to establish relations between two isolated spaces. Moreover, its abstractness, integration capacity and open-ended feature make it easier for people to interpret the process of metaphor translation.

\subsubsection{Classification of Subnetwork Models}

The basic network model of Conceptual Blending Theory introduced above is not adequate enough to explain the specific process of conceptual integration. Therefore, Fauconnier and Turner proposed four different subnetwork models of Conceptual Blending Theory in the book The Way We Think: Conceptual Blending and the Mind's Hidden Complexities, such as Simplex Network, Mirror Network, One-scope Network and Two-scope Network. (Fauconnier \& Turner, 2002: 127)

(1) Simplex Network

Simplex Network, just as its name suggests, is the simplest of the four subnetworks. In this model, Input Space I contains an abstract blank framework, while there isn't any framework in Input Space II, but only elements to fill an empty framework. Moreover, there is no competition between the two input spaces. For instance, Jack is Tim's father. In this case, Input Space I comprises the blank framework that indicates a father-son relationship, while Input Space II includes two elements, namely Jack and Tim. Through a simple cross-space mapping, the framework and the elements are integrated in the blending space to form the emergent structure-Jack is Tim's father.

\section{(2) Mirror Network}

In this model, the generic space contains the organizational framework that the two input spaces share in common, so the different elements in them can usually be matched one by one to form a corresponding relationship. A typical example to explain the model is a debate on the reasoning between Kant and a contemporary professor of philosophy, which is cited by Fauconnier and Turner (1998) in their book The Way We Think: Conceptual Blending And The Mind's Hidden Complexities. In this case, Input Space I contains the element the philosophy professor and other relevant elements such as his diction, 
viewpoint and argument. Similarly, Input Space II includes the element Kant and other elements corresponding to those in Input Space I. Moreover, the content of the generic space is the shared and abstract information structure-two philosophers discuss on a certain question. Through a cross-space mapping, a correspondence is established between Kant and the philosophy professor and between their respective standpoints. Then the elements from the input spaces are selectively projected to the blending space, thus forming the emergent structure-the debate on the question of reasoning between the two sides after a series of cognitive operation processes including the composition, the completion and the elaboration. Finally, the philosophy professor wins the debate, which indicates that the professor's viewpoints are correct and he is an excellent philosopher when the result is projected to Input Space I. However, when projected to Input Space II, the result suggests that Kant's standpoints are not the best although they have some merits. What's more, the influence of the blending space on the input space exactly embodies its existence value.

(3) One-scope Network

In this model, the two input spaces have different organizational frameworks, but only one of them can be projected to the blending space. Therefore, there is also an asymmetry in this type of projection. That is to say, the characteristics of the projected organizational framework determine the nature of the overall integrated content. Li Liangyan (2012: 100 ) indicates that One-scope Network is often used to explain abstract things. Fauconnier and Turner (2002) hold that highly conventional source-target metaphors actually can be explained by One-scope Network, whose source domain is the input space that provides the organizational framework and the target domain is the other input space that needs to be carefully understood.

In order to illustrate the model further, the following example is given: Murdoch knocks out Locacca (Murdoch is a CEO and Locacca is a boxer). The boxing space and the commercial space respectively belong to Input Space I and Input Space II. Through a cross-space mapping, the CEO is matched correspondingly to the boxer and the punch of the boxer is matched to the commercial measure that the CEO takes and so forth. Then the generic space extracts from the two input spaces a somewhat abstract and high-level conceptual structure-the competition between rivals. Finally, the composition, completion and elaboration are carried out in the blending space to generate the emergent structure with new information and meaning, that is, Murdoch beats Locacca in business. During the whole process, the projection from the input spaces to the blending space is asymmetric and the organizational framework in the blending space is only derived from Input Space I, which enables us to understand the abstract action taken by the CEO through the framework provided by the boxing input space.

(4) Two-scope Network

In this model, the two input spaces have different organizational frameworks, both of which are partially projected to the blending space. That is to say, the blending space contains partial structures from the two input spaces at the same time and their integration can form the emergent structure. The famous sentence "The surgeon is a butcher" is a typical example to provide further explanation for Two-scope Network. In this case, the surgeon and the butcher are respectively placed in the two input spaces, whose organizational frameworks differ greatly since butchers use knives to slaughter animals while surgeons use knives to save people. The generic space is that somebody performs a certain operation upon a specific creature through the medium of the knife. Meanwhile, there is an obvious mapping between the two input spaces. For instance, the identity of the butcher corresponds to that of the surgeon, animals correspond to patients, and the butcher's knife corresponds to the scalpel. Then the part of the organizational framework in the butcher input space that is projected to the blending space is the butcher's manner of working, while the one in the surgeon input space is the surgeon's identity. Therefore, the combination of the butcher's working mode and the surgeon's identity in the blending space will create the emergent structure and give the sentence entirely new information and meaning, that is, the surgeon is not good at performing surgery. What's more, the emergent structure in Two-scope Network contains an organizational framework so totally different from those of the two input spaces that this model shows remarkable creativity. (Li Fuyin, 2008: 177)

\section{Metaphor Translation Strategies in Selected Modern Chinese Essays 1}

\subsection{Brief Introduction to Selected Modern Chinese Essays 1}

Zhang Peiji, a famous contemporary Chinese translator, has worked tirelessly in the translation circle for fifty years, whose achievements are manifested in various ways. For example, his translations and monographs exert an extensive influence on academia and are collected by libraries at home and abroad. In addition, he plays an important role in deliberating on and approving of the English manuscripts of many literary works such as The Hurricane by Zhou Libo for foreign publication. All in all, he makes tremendous contributions to the development of translation studies in China and sino-foreign cultural exchanges. 
The series of Selected Modern Chinese Essays including four copies is one of his representative works, which is regarded by numerous translators to have instructional significance and value like textbooks. Meanwhile, this set of books is also one of the few large-scale foreign versions of modern Chinese essays, consisting of a total of 179 masterpieces by 78 well-known writers during the period of May Fourth Movement as well as their English versions. The first copy of the series that the author will focus on contains 52 famous contemporary essays by 32 modern literators such as Lau Shaw, Ba Jin and Xie Wanying and their corresponding translations. Moreover, these collected and translated essays are comparatively representative of the writers' thoughts and writing styles. Therefore, on the one hand, this book opens a new window for not only prose lovers and English lovers, but also scholars who study the intellectuals' ideas during the May Fourth period and the various social phenomena then. On the other hand, the book is of strong authority, great reference value and profound guiding significance, the study of which can facilitate Chinese culture to go global and enable more foreign readers and scholars to understand and appreciate Chinese prose as well as paying attention to the latest research results of metaphor translation strategies in China.

At the same time, this translation is also a reference book for postgraduate entrance examinations of many universities for masters of English literature or translation. It follows then that Zhang Peiji is quite accomplished in the theories and skills of mutual translation between Chinese and English. Therefore, it's very instructive and beneficial to use this translation as research corpus and study on the metaphor translation strategies involved. Besides, this study helps readers more thoroughly understand and more effectively utilize this translation to enrich their relevant theoretical knowledge reserves and enhance their translation skills. It is also conducive for them to grasp the textual thinking mode and have a deeper understanding of the cultural differences between China and the West from a metaphorical level.

\subsection{Metaphor Translation From the Perspective of Conceptual Blending Theory}

Fauconnier and Turner point out that conceptual integration is the source of human cognition and this unique integration capacity has laid a cognitive foundation for the cultural prosperity of human society. In this sense, Conceptual Blending Theory provides a great theoretical perspective for exploring the cognitive process of translingual and cross-cultural translation. Translation is to convert the source language into the target language through a series of procedures such as the translator's understanding of the concept of the source language, reconstruction and conceptual reintegration. Studied from the perspective of conceptual integration, the translation process also has four corresponding mental spaces: Source Text Space, Translator Space, Generic Space and Translation Space, which form the cognitive model of translation as shown in the picture below after mutual projection.

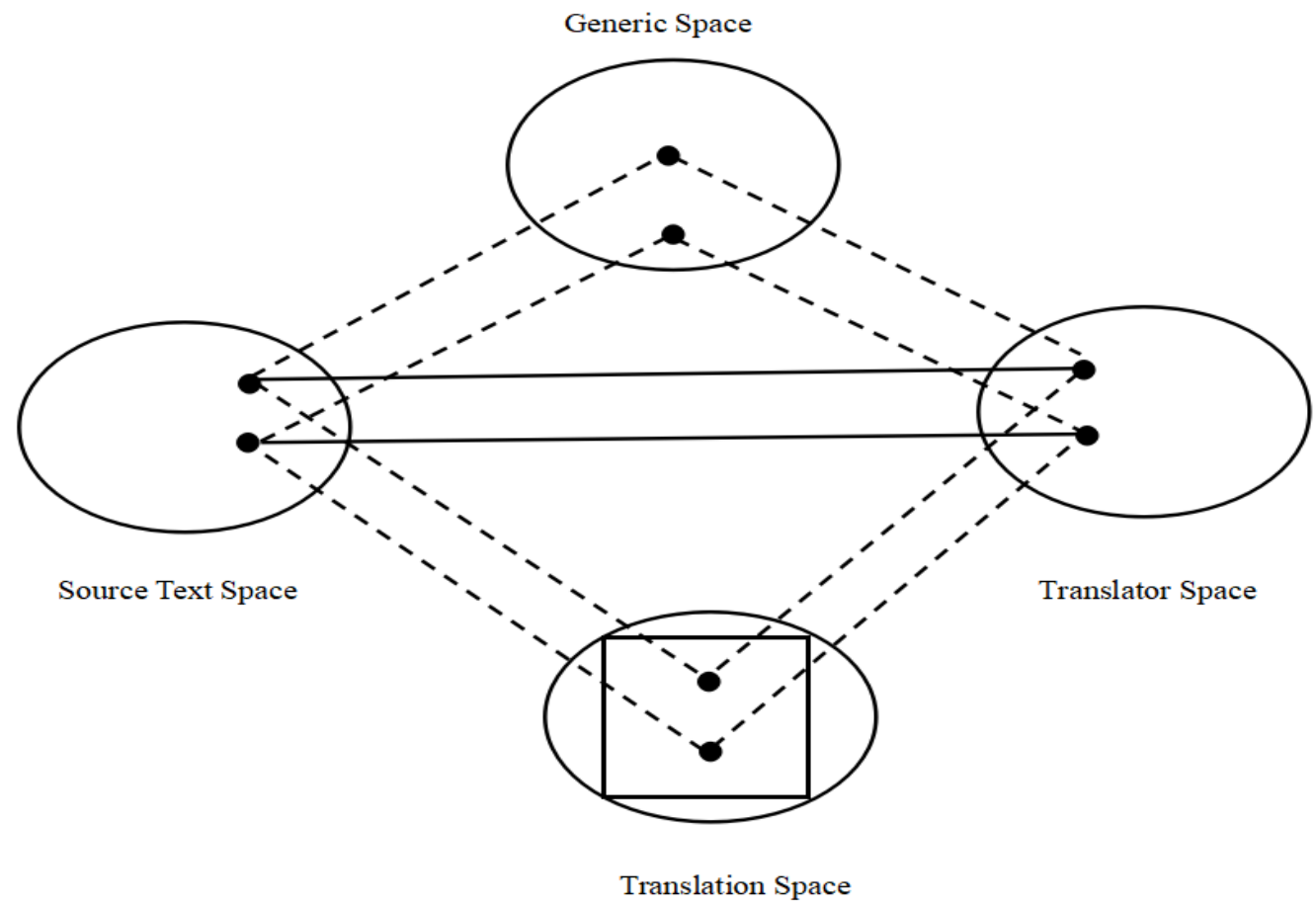

Figure 2. The Cognitive Integration Model of Translation Process (Sun Ya, 2001: 13) 
As Figure. 2 indicates, Source Text Space is made up of various elements such as the source text, grammatical rules of the source language, the cultural system of the source language society, historical allusions and the creation background of the original author. In the case of metaphor translation, the translator needs to analyze and deconstruct the metaphor in the source text before translation and clarify the text structure as well as distinguish between the original conceptual domain and the target conceptual domain.

After the deconstruction of the source text, the translator integrates his own knowledge structure, aesthetic ability, cultural deposits and the linguistic form of the target language to form the translator space. What's more, this space fully embodies the translator's subjectivity in the process of conceptual integration, especially his ability to blend bilingual cultural concepts and establish the mapping relations.

Generic Space contains the thoughts and feelings shared by the translator and the original author and their common experience of the world.

In Translation Space, the mutual mapping between the source text space and the translator space is selectively projected into the translation space through the translator's cognitive operation to generate a translation.

Conceptual Blending Theory offers a whole new understanding that the conceptual integration during translation is a cyclic process of contextual deconstruction, layer-by-layer mapping and innovative integration. (Yin Fulin, 2007: 42) Since it's difficult to achieve one-to-one correspondence between the source text space and the translator space at linguistic and cultural levels, the translator is required to analyze ecological elements of the source text (such as content, form, creation environment, etc.) and cognitive needs of target readers and then use the operation mode of conceptual integration to construct the translated work on a linguistic level.

\subsection{Case Studies of the Metaphor Translation Strategies in This Work}

As Newmark says in his book A Textbook of Translation, "Whilst the central problem of translation is the overall choice of a translation method for a text, the most important particular problem is the translation of metaphor". (Newmark, 2001: 104) Actually, it's acknowledged that metaphor will inevitably embody distinct cultural elements of a nation since it serves as the essence of language and literature. Consequently, how to figure out those cross-cultural factors will pose challenges for translators during the translation of prose, which is an essential component of China's extensive and profound traditional culture. As mentioned above, Conceptual Blending Theory demonstrates strong explanatory power for the formation and translation of metaphors on account of its dynamic network models. In this chapter, the author picks 15 concrete examples of metaphor from 11 articles in Selected Modern Chinese Essays 1 and combines the three subnetwork models of Conceptual Blending Theory to elaborate in detail the metaphor translation strategies adopted by Zhang Peiji.

\subsubsection{Metaphor Translation Strategy for Mirror Network Model}

In this model, the two input spaces share the common organizational framework, which matches the different elements in them one by one to form corresponding relationships. Moreover, the cross-mapping between the spaces becomes quite straightforward. That is to say, it's reliable for the translator to transplant expressions between different cultures. Therefore, translators usually adopt literal translation while preserving the metaphorical image. Here are concrete examples.

\section{Example 1}

Source Text: 父亲说: “事已至此, 不必难过, 好在天无绝人之路!”

\section{选自朱自清的《背影》}

Translated Text: Father said, "Now that things have come to such a pass, it's no use crying. Fortunately, Heaven always leaves one a way out."

\section{from The Sight of Father's Back by Zhu Ziqing}

As we all know, both Chinese and foreigners share a common belief that there is such an existence that takes charge of nature and earthly affairs and they call it the Emperor of Heaven and God respectively. Moreover, it's acknowledged that God will make terrible things show signs of getting promising when human beings are on the verge of despair. For instance, the Bible says: "When God closes a door for you, he will certainly open a window for you." Eileen Chang also has such a well-known saying: "The earth is round because God wants those who go astray or get lost to be reunited." Therefore, the organizational framework activated by the Chinese idiom in the source text space accords with the corresponding one in the translator space, that is, God will give guidance and assistance if human beings are in desperate circumstances. The elements in the two input spaces also form one-to-one mapping relationships. Taking 
into consideration the full correspondence between the original text and the target text at the linguistic level and cognitive level, the translator chooses literal translation with the metaphorical image reserved to make target readers feel the same as original readers. Besides, reverse translation is adopted by translating the negative Chinese expression “无” in an affirmative manner to emphasize the source text's positive meaning-we should be optimistic and positive even if our life is full of hardship and bitterness.

\section{Example 2}

Source Text: 只要往各方去请托, 找关系, 或者干脆买张黑票。

\section{选自叶圣陶的《我坐了木船》}

Translated Text: I can simply go around fishing for help or personal connections, or just buy a "black" ticket.

\section{from I Took a Wooden Boat by Ye Shengtao}

Color terms to a large extent contain metaphors on the basis of human perception and cognition. Etymologically speaking, black refers to the color of specific substances such as ink and coal in both English and Chinese, which gives all people the same visual effects. Moreover, with the knowledge and experiences shared by human beings and similar thinking process, black contains some of the same metaphorical connotations for Chinese and foreigners. More specifically, people always associate black with concealment places or shady sites and activities conducted there tend to be illegal and immoral rather than aboveboard. There are many analogous color terms related to black in both Chinese and English. For instance, “黑钱” and "black money" mean wealth obtained by dubious and unlawful means. “恶行” and "black deeds" refer to criminal and brutal behaviors. Therefore, the translator chooses literal translation and directly translates “黑票” verbatim into "black" ticket although the expression is not commonly used by foreigners. Moreover, the word "black" is put in double quotation marks to activate the corresponding cognitive schema of target readers in combination with the context. Through the literal translation, it not only spreads Chinese culture, but also expands the cognitive structure network of target readers and enriches their relevant expressions.

There are other literally translated metaphors in Selected Modern Chinese Essays 1, whose conceptual integration process of translation generation can be illustrated through Mirror Network Model. Some of them are listed below.

\section{Example 3}

Source Text: 没有在浮沉的人海中，翻过筋斗的和尚，不能算善知识;

$$
\text { 选自卢隐的《恋爱不是游戏》 }
$$

Translated Text: A Buddhist monk without having experienced ups and downs in the sea of mortals will have no claim to true wisdom.

$$
\text { from Love Is Not a Game by Lu Yin }
$$

\section{Example 4}

Source Text: 对这些读者来说, “红学家”就好像是住在“太虚幻境”里的圣人、贤人，与自己无关。

$$
\text { 选自季羡林的《文学批评无用论》 }
$$

Translated Text: To them, the Redologists seem to be sages and men of virtue residing in the "Illusory Land of Great Void" and having nothing whatsoever to do with them.

$$
\text { from On The Futility of Literary Criticism by Ji Xianlin }
$$

\section{Example 5}

Source Text: 但也有一种人, 嘴尖舌长, 能说会道, 自我吹嘘, 滔滔不绝, 像那只爱唱的母鸡一样, 占 着个鸡窝不下蛋。

\section{选自谢逸的《下蛋·唱鸡及其他》}

Translated Text: There are among us, however, another kind of people who, armed with a glib tongue, indulge in incessant self-glorification and, like the above-mentioned cackler, hold on to the coop without laying any egg.

\section{from Egglaying, Cackling, Etc. by Xie Yi}

From the examples above, it follows then that Zhang usually adopts literal translation while preserving the metaphorical image during the translation of metaphors whose translation generation processes accord with the principle of Mirror Network Model. 


\subsubsection{Metaphor Translation Strategy for One-scope Network Model}

A single-scope network contains two input spaces with different organizational frameworks, only one of which is projected and extended to the blending space to generate the framework of the translated text. Wang Bin gives a further explanation of this model by comparing it with the classic working mechanism of Conceptual Metaphor Theory. In his opinion, "The cross-domain mapping of Conceptual Metaphor Theory is one-directional, that is to say, we capture the meaning of one concept in terms of the framework of another. Yet the mapping in the one-scope network is bidirectional, and both the input spaces can be projected to the blending space". (Wang Bin, 2011: 4) This feature enables the translator to generate the translated text with a more flexible two-way choice since the origin of the framework of the blending space is not limited to a certain input space. After summarizing the metaphors whose translation generation processes accord with the principle of One-scope Network Model, the author finds that Zhang mainly adopts two translation strategies including preserving metaphors plus paraphrases and omitting metaphors plus paraphrases. Specific examples are given below to illustrate this model further and the two translation strategies.

This network model is mainly applied in the context showing differences between Chinese and English cultures. When the corresponding linguistic forms of Chinese and English activate different organizational frameworks, translators are faced with the choice of projecting the source text space or the translator space to the translation space, namely the blending space. If translators choose the former, there will be one-way projection from the source text space to the translator space in the translation integration model. The generic space contains the abstract structure of the source text and its linguistic form is reserved in the blending space. Therefore, the generated translation preserves the original metaphor and the paraphrase is added to deepen the understanding of target readers, which is conducive to the dissemination of the cultural information implied in the source text. If translators choose the latter, there will be oneway projection from the translator space to the source text space in the translation integration model. The generic space includes the abstract meaning implied in the translator space and the blending space comprises translators' cognitive association activated by the original linguistic form. The resulting translation omits the original metaphor, so the translator adds paraphrases to strike a chord among target readers and the author of source language and promote their information exchange.

(1) Preserving metaphors plus paraphrases

\section{Example 6}

Source Text: 诸如此类, 其实只是一种社交上的客套, 和 “顿首”“百拜”同是仪式的虚伪。 选自夏西尊的《中年人的寂寞》

Translated Text: All these are, in fact, nothing but civilities of social life, as hypocritical as the polite formula dunshou (kowtow) or baibai (a hundred greetings) used after the signature in old-fashioned Chinese letterwriting.

\section{from Mid-life Loneliness by Xia Mianzun}

The ancient Chinese not only attach great importance to the choice of words, the rhetoric and the grammar when writing letters, but also the format, especially the greeting and salutation at the end of the letter. “顿首” and “百拜” are such examples, which contain metaphors. They are ostensibly two actions of kneeling and bowing, but are often used as honorifics in a letter to express sincere gratitude and respect to the recipient. However, this cultural phenomenon is unique to China, and there is no corresponding content in the translator space. Therefore, Zhang chooses to project the source text space to the translation space and preserves the original metaphor. Since the corresponding English expressions of “顿首” and “百拜” are “kowtow” and “a hundred greetings" respectively, the translation can to the greatest extent retain the original linguistic form and arouse target readers' interest. Meanwhile, the translator adds the paraphrase "used after the signature in old-fashioned Chinese letter-writing" and the Chinese Pinyin of the two words so as to avoid misunderstanding and ambiguity, as well as enabling more foreigners to learn about the letter culture in ancient China and more cognitive models.

There are other similar metaphors in Selected Modern Chinese Essays 1, which are translated not only through the same conceptual integration process, but also the shared strategy. Some of them are listed below.

\section{Example 7}

Source Text: 这自然是书生之见，不免通达的人一笑。

$$
\text { 选自叶圣陶的《我坐了木船》 }
$$

Translated Text: All this is undoubtedly the pedantic view of a bookish person--a view which must sound ridiculous to all sensible gentlemen. 
from I Took a Wooden Boat by Ye Shengtao

\section{Example 8}

Source Text:“你, 是呀, ”她底丈夫病后的无力的声音, “我已经将你出典了.....” 选自柔石的《为奴隶的母亲》

Translated Text: "Yes, we have to part," he answered feebly. "There's somebody willing to hire you as a temporary wife..."

from A Slave Mother by Rou Shi

(2) Omitting metaphors plus paraphrases

Example 9

Source Text: 真正的朋友, 恐怕要算“总角之交”或“竹马之交”了。

选自夏正尊的《中年人的寂寞》

Translated Text: Real friendship between two persons originates perhaps from the time of life when they were children playing innocently together.

from Mid-life Loneliness by Xia Mianzun

“竹马之交” is a very classic and extensively used expression full of the charm of traditional Chinese culture, which contains a metaphor. A bamboo hobbyhorse is a toy horse that children enjoy with their friends when they are carefree and regard as the symbol of their wonderful childhood memories. Therefore, it's used to refer to our innocent and precious childhood. Moreover, the friendship formed at that time is really pure, firm and profound without the involvement of too many conflicts of interest. However, this metaphorical image only exists and makes sense in the source domain and its counterpart can't be found in the target domain. In order to reduce the burden of interpreting information for target readers, the translator chooses to project activated cognitive associations in the translator space to the translation space. Therefore, he omits the original metaphor and adds paraphrases, which causes the lack of cultural information in the source text, but enables target readers to better understand the implicit meaning the author wants to convey.

Other examples using the same metaphor translation strategy are the following.

Example 10

Source Text: 说一句过火的话, 我简直是提心吊胆, 心里不得安宁。

$$
\text { 选自季羡林的《黎明前的北京》 }
$$

Translated Text: To exaggerate it a bit, that keeps me in constant suspense and makes me fidgety. from Predawn Beijing by Ji Xianlin

\section{Example 11}

Source Text: 还有盗罒——实在是最可怜的同胞, 他们种地没得吃, 有力气没处出卖, 当了兵经常饿肚 皮, 无奈何只好出此下策。

$$
\text { 选自叶圣陶的《我坐了木船》 }
$$

Translated Text: To complicate matters, there are bandits lurking around--those pitiful fellow countrymen who, unable to ward off starvation by farming or soldering or whatnot, have been reduced to the disreputable business as a last resort.

from I Took a Wooden Boat by Ye Shengtao

Example 12

Source Text: 父亲因为事忙, 本已说定不送我, 叫旅馆里一个熟识的茶房陪我同去。 选自朱自清的《背影》

Translated Text: Father said he was too busy to go and see me off at the railway station, but would ask a hotel waiter that he knew to accompany me there instead. 


\section{from The Sight of Father's Back by Zhu Ziqing}

In terms of One-scope Network Model, a majority of metaphorical images are omitted to achieve better readability while still some others are preserved to spread Chinese culture and introduce more cognitive models to target readers. However, paraphrases are all added to deepen target readers' understanding of source text.

\subsubsection{Metaphor Translation Strategy for Two-scope Network Model}

Among the four basic subnetwork models mentioned in the previous chapter, the working mechanism of Two-scope Network Model is the most complicated. Its biggest difference with the other three models lies in that both the frameworks and elements of the two input spaces will be projected to the blending space even if they are distinctly different, which will provide sharp and rich conceptual clashes to the emergent structure. Actually, these clashes will not restrain the construction of metaphorical meaning, but provide expansive space for rich imagination and distinctive creation, so the resulting integration can be highly creative. After careful analysis, the author concludes that the translator mainly adopts this translation strategy-replacement with metaphors that accord with the target language in this situation. Moreover, the translator can build a bridge between the source language culture and the target language culture with the help of Twoscope Network Model. Here are specific examples from Selected Modern Chinese Essays 1.

\section{Example 13}

Source Text: 小时候我有一个愿望：我愿在你的庇荫下做一世的孩子。

$$
\text { 选自巴金的《梦》 }
$$

Translated Text: When I was young, I wished I could remain a kid forever under your wing. from Dreams by Ba Jin

It's clear that "you" here refers to the author's father in combination with the context. Many Chinese people like to compare their fathers to trees, since fathers are as stalwart and upright as trees and shelter them from the wind and rain in their minds. However, there isn't such a metaphoric model in English culture. If the original linguistic form is directly projected to the translator space, it will form a conflicting relationship with the organizational framework activated there. Therefore, the source text space projects the metaphoric model-father resembles a tree-to the translation space and the translator space projects the framework stored in the translator's cognitive context to express the deep meaning-under his father's protection. Since target readers are used to the expression "take someone under your wing", the translator replaces the original metaphorical image with "your wing". More significantly, the generated translation not only contains what the author wants to convey, but also the ways of thinking and cognition in both Chinese and English cultures.

There are other metaphors in Selected Modern Chinese Essays 1, the translation process of which can be illustrated through Two-scope Network Model. And the translator mainly adopts the strategy-replacement with metaphors that accord with the target language. Some of them are listed below.

\section{Example 14}

Source Text: 那时乡间豪绅地主的欺压, 衙门差役的横蛮, 逼得母亲和父亲决心要节衣缩食培养出一个 读书人“支撑门户”。

\section{选自朱德的《母亲的回忆》}

Translated Text: My parents, however, faced with the bullying and oppression of the local evil gentry, landlords and yamen bailiffs, decided to scrape up enough money by living a very frugal life to pay for my education so that they could make a scholar of me for the family to keep up appearances.

from Loving Memories of Mother by Zhu De

\section{Example 15}

Source Text: 但是有些记忆经过了多少时间的磨洗也不会消灭。

$$
\text { 选自巴金的《木匠老陈》 }
$$

Translated Text: But some memories will withstand the wear and tear of time.

$$
\text { from Carpenter Lao Chen by Ba Jin }
$$

When it comes to metaphors whose translation generation process can be illustrated through Two-scope Network Model, Zhang mainly adopts the translation strategy: replacement with metaphors that accord with the target language. Therefore, a bridge can be built between the source language culture and the target language culture. 


\section{Conclusion}

It's found that Zhang Peiji selectively and flexibly adopts different metaphor translation strategies based on the three subnetwork models of Conceptual Blending Theory. In Mirror Network Model, the cross-mapping between the spaces is quite straightforward. That is to say, it's reliable for the translator to transplant expressions between different cultures. Therefore, Professor Zhang usually adopts literal translation while preserving the metaphorical image.

When it comes to One-scope Network Model, a majority of metaphorical images are omitted to achieve better readability while still some others are preserved to spread Chinese culture and introduce more cognitive models to target readers. However, paraphrases are all added to deepen target readers' understanding of source text.

With regard to metaphors whose translation generation process can be illustrated through Two-scope Network Model, Zhang mainly adopts the translation strategy: replacement with metaphors that accord with the target language, which enables him to build a bridge between the source language culture and the target language culture.

All in all, the translator should not only take source culture including creation background and related allusions into consideration when translating metaphors, but also attach great importance to target language culture and target readers. Moreover, translation strategies should be flexibly and selectively applied to activate cultural schemata identical or similar to those conveyed in source text, as well as finding an accurate and easy-to-understand expression in target language.

As seen from the study of concrete examples, Conceptual Blending Theory indeed presents strong explanatory power for illustrating the translation process of metaphor. The perspective of conceptual cognition can not only better account for the cognitive motivation behind the translation phenomenon, but also explain their reasons for the choice of translation strategies and skills such as their respective advantages.

\section{References}

Fauconnier, G. (1997). Mappings in Thought and Language. Cambridge: Cambridge University Press.

Fauconnier, G., \& Turner, M. (1998). Conceptual Integration Network. Cognitive Science, 21(2), 133-187. https://doi.org/10.1207/s15516709 $\operatorname{cog} 2202 \_1$

Fauconnier, G., \& Turner, M. (2002). The Way We Think: Conceptual Blending and the Mind's Hidden Complexities. New York: Basic Books.

Li, F. Y. (2008). Introduction to Cognitive Linguistics. Beijing: Beijing University Press.

Li, L. Y. (2012). A Cognitive Study on Poetic Metaphors Based on the Conceptual Blending Theory. Foreign Language Research, (5), 98-101. https://doi.org/10.16263/j.cnki.23-1071/h.2012.05.021

Li, S. (2020). The Meaning Construction of Indirect Speech Acts: From the Perspective of Conceptual Integration Theory. Journal of Xiangnan University, 41(6), 64-68. https://doi.org/10.3969/j.issn.1672-8173.2020.06.013

Newmark, P. (2001). A Textbook of Translation. Shanghai: Shanghai Foreign Language Education Press.

Sun, Y. (2001). Mental Space Theory and Translation. Shanghai Journal of Translators for Science and Technology, (4), 12-14. https://doi.org/10.3969/j.issn.1672-9358.2001.04.003

Wang, B. (2011). Translating in Blending Revisited. Journal of University of Shanghai for Science and Technology. 33(1), 1-5, 19. https://doi.org/10.13256/j.cnki.jusst.sse.2011.01.007

$\mathrm{Xu}$, Y. J. (2020). An Analysis on the Choice of Translating Strategies from Skopos Theory Perspective-Take Zhang Peiji's Selected Modern Chinese Essays for Example. Journal of Shanxi Datong University, 34(6), 96-99. https://doi.org/CNKI:SUN:MZBL.0.2020-14-070.

Yin, F. L. (2007). A Study on the Inter-subjectivity of Translation in the Mode of Conceptual Blending. Foreign Languages and Their Teaching, (11), 41-44. https://doi.org/CNKI:SUN:WYWJ.0.2007-11-011

\section{Copyrights}

Copyright for this article is retained by the author(s), with first publication rights granted to the journal.

This is an open-access article distributed under the terms and conditions of the Creative Commons Attribution license (http://creativecommons.org/licenses/by/4.0/). 